\title{
Machine Learning Assisted Nanomaterials as Super hydrophobic Coatings for Antiviral Functionalities to Fight COVID-19
}

\author{
Saranya J*1, Suganthi $\mathrm{S}^{1}$, Sheena Christabel Pravin ${ }^{2}$, Selvakumar V. S. ${ }^{3}$ \\ Assistant Professor, Department of Electronics and Communication Engineering, \\ Rajalakshmi Engineering College, Thandalam - 602105, Tamilnadu, India. \\ *Corresponding Author E- mail id: saranya.j@rajalakshmi.edu.in
}

\begin{abstract}
The Coronavirus Disease-19 (COVID-19) pandemic has emerged into a severe problem. The contact spreading of the virus poses more threat to the people. The fast spreading of the virus is due to its endurance for several hours in aerosol and on flat surfaces. This necessitates the need for super hydrophobic coatings on the surfaces of Personal Protection Equipment (PPE), furniture and diagnostic equipment in hospitals. The nanomaterials have been used for inducing anti-viral and anti-bacterial characteristics to the hydrophobic solutions, converting them into super hydrophobic solutions. These nanomaterials on the hydrophobic solutions, encapsulate, suppress and eliminate viruses. For example, graphene has the ability to trap the viruses and transfer electric charges to destroy them. In this review, effective combinations and formulations of nanoparticles for disinfecting surfaces against microbes are presented. Also, the various coating techniques available for converting the fabric surfaces into a super-hydrophobic material is expounded. Further, the incorporation of machine learning models for tuning the nanomaterial parameters is also portrayed.
\end{abstract}

Keywords - Anti-viral; Graphene; Health; Nanomaterials; Pandemic; Super Hydrophobic; Machine Learning.

\section{Introduction}

Severe Acute Respiratory Syndrome-Corona Virus (SARS-CoV-2), the virus causing COVID-19, is spreading worldwide at a fast pace. Stated as a pandemic by the WHO, the world is currently facing the largest health crisis of the century. First reported in 2019 in Wuhan, China, the virus SARS-CoV-2 caused the disease COVID-19, ranging from milder flu-like symptoms and fever to severe lung disease and failure of multiple organs, mostly fatal. The variants of the Corona Virus (CoV) are on the rise, which has eventually increased the rate of fatalities in the second and subsequent waves of the pandemic.

SARS-CoV-2 is a new virus in the Beta corona virus kind [1]. Although it is similar to SARS-CoV in its genetic structure, its invasion into human body is different. It is more transmissible and has post challenges for the scientists in understanding the human immune responses. As shown in Figure 1, the corona viral genome includes four operational proteins: the Spike denoted as 'S', Nucleocapsid protein denoted as ' $\mathrm{N}$ ', Membrane protein ' $\mathrm{M}$ ' and the Envelope protein 'E'. The Spike protein facilitates the admittance of $\mathrm{CoV}$ into the focussed cell. Its structure includes a miniscule of intracellular tail, an anchor between the membranes and a large ectodomain with a receptor binding sub-unit ' $\mathrm{S} 1$ ' and another sub-unit 'S2', which is responsible for membrane-fusing.

Coronaviruses belong to the family of RNA viruses [1]; they are responsible for infecting the upper respiratory and gastrointestinal tract of the infected person. The person experiences difficulties such as cough and fever, and in severe cases breathing difficulties occur, leading to death of the individual.

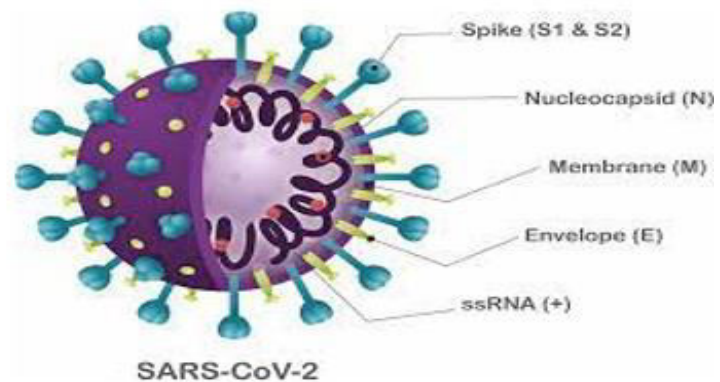

Fig.1: Structure of SARS-CoV-2 Virus [1]

The prime focus of this research study, is to present a keen summary of the role of nanomaterials and their formulations that trap, suppress and kill the virus. Also, the machine learning based parameter tuning of the nanostructure is also discussed. This research paper has been ordered as follows: Nanomaterials - an overview, followed by applications of nanomaterials, antiviral potential of nanomaterials, synthesis of nano formulation and finally the coating methods commonly adopted using the formulation.

\section{Nanomaterials - An Overview}

Nanoparticles (NPs), widely referred as nanomaterials, have been used as agents against viruses, for treating viral contagions. Variants of nanoparticles are used, grounded on

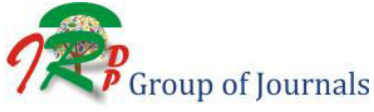


the size and shape of the virus. The major class of nanomaterials are silver, gold, titanium, organic NPs, liposomes, dendrimers and polymers. The metal oxides in particular are versatile in their applications, starting from therapeutic doses, external drugs in the form of gels, pain relieving sprays, antiviral coatings etc. [2]. The fundamental reason behind this ubiquitous application of these nanomaterials is that, their properties can be adjusted by changing the synthesis constraints during wet chemical processes.

The nanoparticles are widely used in many industrial applications including petrochemical and textile products [4]. The immobilization of NPs on fabric has gained importance recently and is an active research area after the emergence of COVID-19. The fabric becomes resistant to water, stain and odour, after the application of nanomaterials. Also, the nanomaterial coating achieves antiviral, anti-bacterial and UV-light protection. Some inorganic nanomaterials when coated on the fabric, convert it to a conducting material. Such conducting fabric or paper sheets are used in relatively low-cost electronic devices such as solar cells, electronic and optical sensors, microelectronic devices etc. Owing to their large surface area, the conductive silver-based cotton fabric possesses high electrical conductivity and is useful in sulphide detection and monitoring applications. Ag Nanoparticles, along with the binding chemicals can be coated by employing print-screening, spray, ultrasonic dip coating, padding squeezing methods. Super hydrophobic materials, find application in biomimetic, preservation of stone-based and metallic artworks also. They prevent corrosion and degradation of the material because of their water repellent nature. With afore background on nanoparticles, the novel applications of nanomaterials, viz. enhancing the antiviral properties of textiles, using metallic nanoparticles, are presented.

\subsection{Antiviral Properties of Metal Nanoparticles against Viral Variants}

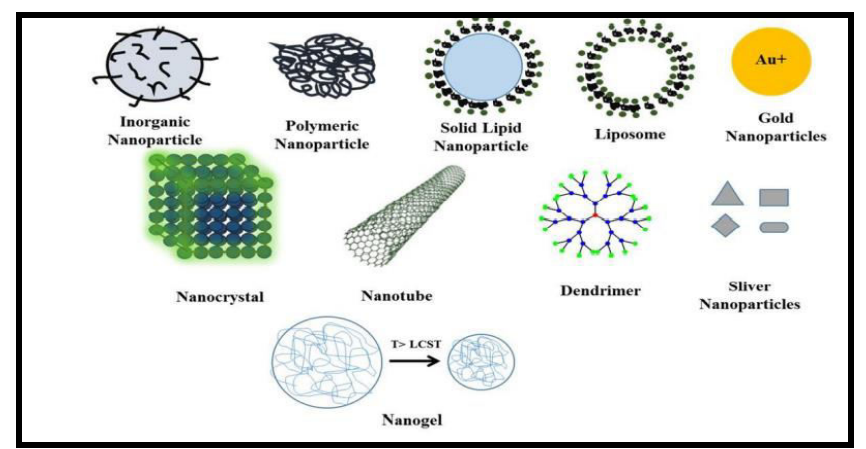

Fig. 2: Antiviral nanoparticles of various sorts are utilized as antiviral medicines and delivery agents in antiviral therapy
Metallic nanoparticles are versatile in terms of their antiviral and therapeutic properties. The antiviral characteristics, features and functionalities of various metalbased nanoparticles against different types of viruses are shown in Figure 2.

\subsubsection{Human Immunodeficiency Virus (HIV-1)}

Silver nanoparticles inhibit the growth of HIV-1, by intermingling with the disulphide bond area in the Cluster of Differentiation-4binding region of the glycoprotein (gp120) receptor on the HIV-1viral enclosure [3]. Foamy carbon silver nanoparticles, Poly N-Vinyl-2-Pyrrolidone (PVP) coated silver nanoparticles, and Bovine Serum Albumin (BSA) coated silver nanoparticles were investigated by [4], all of which had distinctive surface behaviour. The interactions of silver nanoparticles with HIV-1 were studied using a scanning transmission electron microscope with a high angle annular dark field. It was discovered that $1-10 \mathrm{~nm}$ silver nanoparticles interact with the gp120 glycoprotein's sulphur-bearing residues. Due to their coated surfaces, PVP-coated and BSA linked nanoparticles had slightly decreased inhibitory efficiency. Foamy carbon silver nanoparticles, on the other hand, have higher inhibitory potential [4]. PVP coated silver nanoparticles were also found to be an effective virucidal agent in a luciferase-based assay. By inhibiting the gp120CD4 contact and attachment, silver nanoparticles hindered the early phases of HIV-1 propagation [3]. Nanoparticles were employed as a covering for polyuretan condoms. Such nanosilver coated condoms inhibited HIV-1, HSV-1, HSV2 , as well as numerous bacteria and fungi, and can be considered a true broad-spectrum antimicrobial agent against pathogens, which were the cause for sexually transmitted diseases. Their subsequent research revealed that AgNPs produced by fungi can reduce HSV-1 and 2 infectivity in a dose-dependent manner, demonstrating the broad potential of adopting green-chemistry method to develop antiviral drugs [6].

\subsubsection{Hepatitis B Virus}

Silver nanoparticles inhibit the replication of Hepatitis B Virus (HBV) replication, when they are bound to the DNA of the virus. It leads to the synthesis of HBV RNA and the creation of extracellular virions [5]. The antiviral properties of poly-dispersed silver nanoparticles were investigated in action over $\mathrm{HBV}$ and discovered that nanoparticles with diameters of $10 \mathrm{~nm}$ and $50 \mathrm{~nm}$ had antiviral properties, without cellular toxicity, whereas nanoparticles with diameters of $800 \mathrm{~nm}$ had higher cellular toxicity. Using a human hepatoma cell line, the antiviral impacts of silver nanoparticles on HBV were studied. Silver nanoparticles of $10 \mathrm{~nm}$ and $50 \mathrm{~nm}$ exhibited robust 
fastening attraction for HBV DNA and other extracellular viruses.

\subsubsection{Influenza Virus}

The antiviral activities of nano-silver against influenza virus were investigated by [2]. They used nano-silver to treat Madin-Darbey Canin Kidney (MDCK) cell cultures and studied the impacts, through and after the viral infection. Nano-silver, at concentrations up to $1 \mu \mathrm{g} / \mathrm{ml}$ was reported to be less toxic to MDCK cells, when the effects of varios nano-silver concentrations were examined. The haem agglutination (HA) test was used to analyze the inhibitory effects of nano-silver on the virus and its cytotoxicity, and it was found that nano-silver can destroy viral membrane glycoproteins.

\subsection{Synthesis of Metal Nanoparticles}

Metal oxide nanoparticles have been synthesized using a variety of methods, viz., microwave-assisted technique, precipitation, thermal decomposition, reverse micelle, solgel, solvothermal and flow synthesis. Precipitation, Sol-gel and reverse micelle have been thoroughly investigated in the literature. Illustrations on microwave-assisted synthesis, thermal breakdown and hydrothermal methods that can be moved up without compromising the eminence of metal oxide nanoparticles are presented in this review as shown in Table1.

Table 1. Wet Chemical procedures for synthesis of metal oxide nanoparticles

\begin{tabular}{|l|l|l|l|}
\hline \multicolumn{1}{|c|}{ Methods } & Thermal Decomposition & Microwave assisted synthesis & Solvothermal \\
\hline Characteristics & $\begin{array}{l}\text { Crystallinity property of } \\
\text { nanomaterial based on time and } \\
\text { temperature. }\end{array}$ & $\begin{array}{l}\text { Variation in the crystallinity } \\
\text { property based on type of } \\
\text { precursor. }\end{array}$ & $\begin{array}{l}\text { Crystallinity property } \\
\text { of nanomaterial varies } \\
\text { as a function of time. }\end{array}$ \\
\hline $\begin{array}{l}\text { Nucleation and } \\
\text { growth mechanism }\end{array}$ & $\begin{array}{l}\text { Nucleation is faster and growth } \\
\text { mechanism is due to quantum of } \\
\text { monomer units present in it }\end{array}$ & Both Nucleation \& growth are fast. & $\begin{array}{l}\text { Rate of nucleation \& } \\
\text { growth are moderate in } \\
\text { speed. }\end{array}$ \\
\hline Conditions & $\begin{array}{l}\text { High Temperature \& inert } \\
\text { atmosphere. }\end{array}$ & $\begin{array}{l}\text { Both temperature \& } \\
\text { pressure are high. }\end{array}$ \\
\hline Solvent & $\begin{array}{l}\text { Higher boiling solvent } \\
\text { pressure. }\end{array}$ & Any solvent \\
\hline Reproducibility & $\begin{array}{l}\text { Batch to batch variation (Quick } \\
\text { nucleation, whereas small variation } \\
\text { in concentration, addition rate and } \\
\text { temperature variation affects the } \\
\text { reaction kinetics) }\end{array}$ & $\begin{array}{l}\text { Batch to batch variation } \text { (Quick } \\
\text { nucleation, whereas small variation } \\
\text { in concentration., addition rate and } \\
\text { temperature variation affects the } \\
\text { reaction kinetics) }\end{array}$ & Reproducible \\
\hline
\end{tabular}

Table 2. Microwave-assisted synthesis of metal oxide nanoparticles

\begin{tabular}{|l|l|l|l|l|}
\hline Metal Oxide & Precursor & Solvent & Temp ${ }^{\circ}$ C [Time] & Size \& Shape \\
\hline Fe3O4 [7] & Fe(acac $)_{3}$ & $\begin{array}{l}1,2 \text { hexadecanediol Dibenzyl } \\
\text { ether, }[\mathrm{BMIM}][\mathrm{BF} 4]\end{array}$ & $220[5 \mathrm{~min}]$ & $6 \mathrm{~nm}($ monosiperse $3 \%)$ \\
\hline $\mathrm{ZnO}[8]$ & $\mathrm{Zn}(\mathrm{Ac})_{2} .2 \mathrm{H}_{2} \mathrm{O}$ & Benzyl alcohol & $393[10 \mathrm{~min}]$ & Sphere $(5.8 \mathrm{~nm})$ \\
\hline $\mathrm{TiO} 2[9]$ & $\begin{array}{l}\text { Thiobenzoate } \\
\text { Complex with } \\
\mathrm{Ti}\end{array}$ & $\begin{array}{l}\text { Benzyl alcohol } \\
\text { Ethanol }\end{array}$ & $\begin{array}{l}{[30 \mathrm{~min}]} \\
{[10 \mathrm{~min}]}\end{array}$ & $\begin{array}{l}7 \mathrm{~nm} \\
5 \mathrm{~nm}(295 \mathrm{~nm} \\
\text { aggregates })\end{array}$ \\
\hline
\end{tabular}

Table 3. Synthesis of metal oxide nanoparticles using thermal decomposition

\begin{tabular}{|c|c|c|c|c|c|}
\hline $\begin{array}{l}\text { Metal Oxide } \\
\text { [Ref.] }\end{array}$ & Metal Precursor & Surfactant & Solvent & $\begin{array}{l}\text { Temp }{ }^{\circ} \mathrm{C} \\
\text { [Time] }\end{array}$ & Size \& Shape \\
\hline Fe2O3 [10] & $\mathrm{Fe}(\mathrm{OA})_{3}$ & NA & $\begin{array}{l}\text { Hexadecene } \\
\text { Octyl ether } \\
\text { Octadecene } \\
\text { Eicosene } \\
\text { Trioctylamine }\end{array}$ & $\begin{array}{c}274[30 \mathrm{~min}] \\
287[30 \mathrm{~min}] \\
320[30 \mathrm{~min}] \\
330[30 \mathrm{~min}] \\
365[30 \mathrm{~min}]\end{array}$ & $\begin{array}{l}5 \mathrm{~nm} \text { Sphere (yield 95\%) } \\
9 \mathrm{~nm} \text { Sphere } \\
12 \mathrm{~nm} \text { Sphere } \\
16 \mathrm{~nm} \text { Sphere } \\
22 \mathrm{~nm} \text { Sphere }\end{array}$ \\
\hline
\end{tabular}




\begin{tabular}{|l|l|l|l|l|l|}
\hline $\mathrm{FeO}[11]$ & Fe-Oleate & Gd-oleate & Octadecene & $320[30 \mathrm{~min}]$ & $\begin{array}{l}12.8 \mathrm{~nm}-7.1 \mathrm{~nm} \\
\text { Sphere/cube }\end{array}$ \\
\hline $\begin{array}{l}\mathrm{NiFe} 2 \mathrm{O} 4 \\
{[12]}\end{array}$ & $\begin{array}{l}\text { Ni-Oleate } \\
\text { Fe-Oleate }\end{array}$ & OA & Octadecene & $305[30 \mathrm{~min}]$ & $9.6 \mathrm{~nm}$ Spherical \\
\hline
\end{tabular}

Table 4. Synthesis of metal oxide nanoparticles using Solvothermal method

\begin{tabular}{|l|l|l|l|l|}
\hline Metal Oxide & Metal Precursor & Solvent & Temp ${ }^{\circ} \mathrm{C}[$ Time $]$ & Size \& Shape \\
\hline $\mathrm{Cu}_{2} \mathrm{O}[13]$ & $\mathrm{Cu}(\mathrm{Ac})_{2}$ & Dimethoxyaniline & $180[10 \mathrm{~h}]$ & $\mathrm{D} \sim 40-70 \mathrm{~nm}, \mathrm{~L}<100 \mu \mathrm{m}($ Wire $)$ \\
\hline$\gamma-\mathrm{Fe} 2 \mathrm{O} 3[14]$ & $\mathrm{Fe}(\mathrm{AcAc})_{3}$ & 1,4-butanediol Toluene & $250[2 \mathrm{~h}] 250[2 \mathrm{~h}]$ & $30 \mathrm{~nm}($ Sphere $) \quad 57 \mathrm{~nm}($ Sphere $)$ \\
\hline $\mathrm{ZnO}[15]$ & $\mathrm{Zn}(\mathrm{Ac}) 2.2 \mathrm{H} 2 \mathrm{O}$ & $\begin{array}{c}\text { Methanol } \\
\text { LiOH }\end{array}$ & $200[6 \mathrm{~h}]$ & \\
& $\mathrm{Ni}(\mathrm{Ac}) 2.4 \mathrm{H} 2 \mathrm{O}$ & $\mathrm{LH}$ & \\
\hline
\end{tabular}

Table 2,3,4 depict the shape \& size of the nanoparticles based on the choice of wet chemical procedure, type of solvent, operating temperature, incubation time \& type of nanoparticles.

\subsection{Coating Techniques for Super-Hydrophobic Surfaces}

The recent progresses in the field of super hydrophobic surfaces have been investigated in this research study. The right combination of roughness, surface texture and low surface energy materials results in super hydrophobicity. A homogeneous distribution of nanomaterials on a substrate with precise density control is required in this case. When the substrate is flexible or has an anisotropic shape, this problem becomes more difficult. There are two types of nanomaterial deposition methods: dry and wet (solutionbased) approaches. The thin film of nanomaterials is produced directly from a precursor using dry techniques such as chemical vapor deposition. Wet techniques scatter nanoparticles in a solvent before fabricating a film out of the solution. Table 5 represents various coating methods that are popular in realizing self -cleaning surfaces.

Table 5. Summary of Super hydrophobic Coating Methods

\begin{tabular}{|c|c|c|c|c|c|}
\hline Method & Coating Material & Base Material & $\begin{array}{l}\text { Contact } \\
\text { Angle }\end{array}$ & Additional Properties & $\begin{array}{l}\text { Referenc } \\
\text { es }\end{array}$ \\
\hline Sol-gel & Alumina & Glass & $165^{\circ}$ & $\begin{array}{l}\text { Light transmittance of } \\
92 \% \text { for roughness of } \\
20-50 \mathrm{~nm}\end{array}$ & 18 \\
\hline $\begin{array}{l}\text { Chemical vapor } \\
\text { deposition }\end{array}$ & $\begin{array}{l}\text { Silicone (polysiloxane) } \\
\text { nanofilaments }\end{array}$ & $\begin{array}{ll}\text { Glass } & \text { Titanium } \\
\text { Aluminum } & \end{array}$ & $\begin{array}{l}156 \text { and } \\
163[\mathrm{a}] \\
166168\end{array}$ & $\begin{array}{l}\text { Coated glass has a better } \\
\text { light transmittance than } \\
\text { untreated glass. }\end{array}$ & 19 \\
\hline Drop casting & $\begin{array}{l}\text { Teflon-graphite } \\
\text { composite }\end{array}$ & Glass and Kaplan film & $\begin{array}{l}157 \\
\& 140[\mathrm{a}]\end{array}$ & $\begin{array}{l}\text { Good electrical } \\
\text { conductivity in the order } \\
\text { of } 10^{3} \mathrm{Sm}^{-1}\end{array}$ & 20 \\
\hline Spin coating & $\begin{array}{l}\text { C9F20 for aluminum, } \\
\text { poly(dimethylsiloxane) } \\
\text { vinyl terminated } \\
\text { (PDMSVT) for 2024Al } \\
\end{array}$ & $\begin{array}{l}\text { AluminumAluminum } \\
\text { alloy (2024Al) }\end{array}$ & 168161 & - & 21 \\
\hline Etching & Si with $\mathrm{XeF} 2$ & Silicon surface & $156^{\circ}$ & - & 22 \\
\hline $\begin{array}{l}\text { Nanoimprint } \\
\text { Lithography } \quad+ \\
\text { Etching }\end{array}$ & Photoresist & Silicon Substrate & $164^{\circ}$ & - & 23 \\
\hline
\end{tabular}

The characteristics of super hydrophobic coating methods have been discussed. Based on the application and other factors such as time, cost of coating, durability, any of the afore-mentioned processes can be taken and adopted. The quality of coating can be confirmed using basic characterizations such as Scanning Electron Microscopy (SEM), Transmission Electron Microscopy (TEM), and water contact angle measurement etc.

\section{Machine Learning Models for Tuning the Nanomaterials}

Various parameters surrounding the choice of nanomaterials and their applications can be tuned and evaluated by machine learning models. In recent times, machine learning - based nano-coatings are in the rise, 
owing to their ability to make experimentation easier. Machine learning models can be used to characterise surface attributes such as adhesion forces, water contact and sliding angles, and features of the morphology that determine how water droplets bounce over a surface during self-cleaning [24]. The researchers also established some specific goals for themselves, stating that a self-cleaning surface's water contact angle must be more than 150 degrees. Super hydrophobicity on a silica surface. The water contact and sliding angles are shown in the insets. Machine learning models can help map out the degree of influence of each parameter on the target, making experimentation easier.

The potential of artificial intelligence (AI) in the identification of novel biointerfaces and the engineering of materials surfaces, particularly for biomedical applications were investigated [25]. Controlling wettability through design-controlled hierarchical surfaces or microtextured biointerfaces, whose design is aided by Artificial Neural Networks and whose performance is predicted (ANN). To build design maps for super hydrophobic polymer topographies, [26] used a hybrid approach that included experimental methodologies, numerical simulations, and machine learning (ML) algorithms. The maximum water contact angle (WCA) and Laplace pressure were two super hydrophobic properties studied. The geometries of an isotropic pillar structure at micrometre and submicrometer length scales were used as design criteria. The experimental results confirmed the Finite Element Method (FEM), which was used to generate a labelled dataset for ML training. The topographic parameters (width $\mathrm{W}$, height $\mathrm{H}$, and pitch $\mathrm{P}$ ) with the accompanying WCA and Laplace pressure were then trained on the labelled database using ANN models. The ANN models revealed a variety of nonlinear correlations between topographic design factors and WCA and Laplace pressure, as well as significant differences in micrometre and sub-micrometer length scales. Topography design parameters that span design maps provide optimal design or trade off parameters. The promise of ANN as a quick design tool for surface topography exploration is demonstrated in this study.

A promising method for creating water-repellent surfaces for most anti-icing and self-cleaning applications was identified by [27]. Various parameters such as the morphology of impacting water drops on surfaces as a function of drop properties such as drop diameter, density, viscosity, and surface tension, kinematic parameters such as velocity, and surface features such as the contact angle, contact angle hysteresis, and surface roughness were used to investigate drop interactions with hydrophobic and super hydrophobic surfaces in depth. The behaviour of striking drops on hydrophobic and super hydrophobic surfaces was predicted using machine learning.

\section{Conclusion}

A research review has been presented, highlighting the synthesis and coating techniques of Nanoparticles on textiles to enhance their super hydrophobic functionalities. Also, machine learning assisted super hydrophobic nano materials have been presented, which are in the rise owing to the ease of tuning the varied parameters associated with the nanomaterials. The super hydrophobic materials have an important role in combatting the COVID virus and provide safer surfaces for consumers in various fields, including health-care.

\section{References}

[1] A.G. Harrison, T. Lin and P. Wang, Mechanisms of SARS-CoV-2 transmission and pathogenesis, Trends in Immunology (2020), https://doi.org/10.1016/ j.it.2020.10.004

[2] Mehrbod P., Motamed N., Tabatabaeian M., Soleymani Estiar R., Amini E., Shahidi M., Kheyri M.T. , 2009, 'In Vitro Antiviral Effect of "Nanosilver" On Influenza Virus', Daru Journal Of Pharmaceutical Science Spring 2009, Volume 17, Number 2; Page 88 to 93 .

[3] Lara HH, Ayala-Nunez NV, Ixtepan-Turrent L, Rodriguez-Padilla C. (2010). Mode of antiviral action of silver nanoparticles against HIV1. J Nanobiotechnol 8:1 (10 pages).

[4] Elechiguerra JL, Burt JL, Morones JR, et al. (2005). Interaction of silver nanoparticles with HIV-1. J Nanobiotechnol 3:6 .

[5] Lu L, Sun RW, Chen R, et al. (2008). Silver nanoparticles inhibit hepatitis B virus replication. AntivirTher 13:253-62.

[6] Fayaz AM, Ao Z, Girilal M, et al. (2012). Inactivation of microbial infectiousness by silver-nanoparticles coated condoms: a new approach to inhibit HIV- and HVS transmitted infection. Int $\mathbf{J}$ Nanomedicine 7:5007-18.

[7] H. Hu, H. Yang, P. Huang, D. Cui, Y. Peng, J. Zhang, F. Lu, J. Lian and D. Shi, Chemical Communications, 2010, 46, 3866-3868.

[8] I. Bilecka, P. Elser and M. Niederberger, ACS nano, 2009, 3, $467-$ 477.

[9] M. I. Dar, A. K. Chandiran, M. Gratzel, M. K. Nazeeruddin and S. A. Shivashankar, Journal of Materials Chemistry A, 2014, 2, 1662-1667.

[10] J. Park, K. An, Y. Hwang, J.-G. Park, H.-J. Noh, J.-Y. Kim, J.- H. Park, N.-M. Hwang and T. Hyeon, Nature materials, 2004, 3, 891 895.

[11] H.-W. Song, N.-Y. Kim, J.-e. Park, J.-H. Ko, R. J. Hickey, Y.- H. Kim and S.-J. Park, Nanoscale, 2017.

[12] J. A. Bau, P. Li, A. J. Marenco, S. Trudel, B. C. Olsen, E. J. Luber and J. M. Buriak, Chemistry of Materials, 2014, 26, 4796-4804.

[13] Y. Tan, X. Xue, Q. Peng, H. Zhao, T. Wang and Y. Li, Nano Letters, 2007, 7, 3723-3728

[14] S. Chaianansutcharit, O. Mekasuwandumrong and P. Praserthdam, Crystal Growth \& Design, 2006, 6, 40-45.

[15] H. Zhang, X. Yu and P. V. Braun, Nature nanotechnology, 2011, 6, 277-281.

[16] S. Chaianansutcharit, O. Mekasuwandumrong and P. Praserthdam, Crystal Growth \& Design, 2006, 6, 40-45.

[17] H. Zhang, X. Yu and P. V. Braun, Nature nanotechnology, 2011, 6, 277-281.

[18] Artus, GRJ, Jung, S, Zimmermann, J, Gautschi, HP, Marquardt, K, Seeger, S, "Silicone Nanofilaments and Their Application as Superhydrophobic Coatings.', Adv. Mater., 18 2758-2762 (2006).

[19] Bayer, IS, Caramia, V, Fragouli, D, Spano, F, Cingolanic, R, Athanassiou, A, "Electrically Conductive and High Temperature Resistant Superhydrophobic Composite Films from Colloidal Graphite.', J. Mater. Chem., 22 2057-2062 (2012). 
[20] Guo, Z, Zhou, F, Hao, J, Liu, W, "Stable Biomimetic SuperHydrophobic Engineering Materials.” J. Am. Chem. Soc., 127 15670-15671 (2005)

[21] Kwon, Y, Patankar, N, Choi, J, Lee, J, “Design of Surface Hierarchy for Extreme Hydrophobicity.' Langmuir, 25 (11) 6129-6136 (2009)

[22] Pozzato, A, Zilio, SD, Fois, G, Vendramin, D, Mistura, G, Belotti, M, Chen, Y, Natali, M, "Superhydrophobic Surfaces Fabricated by Nanoimprint Lithography.'” Microelectron. Eng., 83 884-888 (2006).

[23] S.Suganthi, L.Sujatha, V.S.Selvakumar, P.Rajasekar and K.Karthikeyan , 2020, 'Fabrication and Study of On-Chip Electrode for Capacitive Type Uric Acid Sensor' vol.63 issue 5, Solid State Technology, pp.4019-4027.

[24] Xia Zhang, Ding, B., Cheng, R., Dixon, S. C., Lu, Y., Adv. Sci.2018, 5, 1700520. https://doi.org/10.1002/advs.476
[25] Azimi Yancheshme, S. Hassantabar, K. Maghsoudi, S. Keshavarzi, R. Jafari, G. Momen, Integration of experimental analysis and machine learning to predict drop behavior on superhydrophobic surfaces, Chemical Engineering Journal, Volume 417, 2021, 127898.

[26] Andrés Díaz Lantada, Francisco Franco-Martínez and Klaus Bade, "Artificial Intelligence Aided Design of Microtextured Surfaces: Application to Controlling Wettability", Nanomaterials (Basel), 2020, 10(11), 2287.

[27] Qiang Wang, Jarrett J Dumond, Jarren Teo, and Hong Yee Low,"Superhydrophobic Polymer Topography Design Assisted by Machine Learning Algorithms", ACS Applied Materials \& Interfaces 202113 (25), 30155-30164, DOI: 10.1021/acsami.1c04473.

[28] A. V. Nikam, B. L. V. Prasad, A. A. Kulkarni, Wet chemical synthesis of metal oxide nanoparticles: a review, CrystEngComm, vol. 20 , no. 35 , pp. 5091-5107. 